\title{
Molecular and biochemical characterisation of a novel mutation in POLG associated with Alpers syndrome
}

\author{
André Schaller ${ }^{1 *}$, Dagmar Hahn², Christopher B Jackson ${ }^{1}$, Ilse Kern ${ }^{3}$, Christophe Chardot $^{4,5}$, Dominique C Belli ${ }^{3}$,
} Sabina Gallati', Jean-Marc Nuoffer ${ }^{2}$

\begin{abstract}
Background: DNA polymerase $\gamma(P O L G)$ is the only known mitochondrial DNA (mtDNA) polymerase. It mediates mtDNA replication and base excision repair. Mutations in the POLG gene lead to reduction of functional mtDNA (mtDNA depletion and/or deletions) and are therefore predicted to result in defective oxidative phosphorylation (OXPHOS). Many mutations map to the polymerase and exonuclease domains of the enzyme and produce a broad clinical spectrum. The most frequent mutation p.A467T is localised in the linker region between these domains. In compound heterozygote patients the p.A467T mutation has been described to be associated amongst others with fatal childhood encephalopathy. These patients have a poorer survival rate compared to homozygotes.
\end{abstract}

Methods: mtDNA content in various tissues (fibroblasts, muscle and liver) was quantified using quantitative PCR (qPCR). OXPHOS activities in the same tissues were assessed using spectrophotometric methods and catalytic stain of BN-PAGE.

Results: We characterise a novel splice site mutation in POLG found in trans with the p.A467T mutation in a 3.5 years old boy with valproic acid induced acute liver failure (Alpers-Huttenlocher syndrome). These mutations result in a tissue specific depletion of the mtDNA which correlates with the OXPHOS-activities.

Conclusions: mtDNA depletion can be expressed in a high tissue-specific manner and confirms the need to analyse primary tissue. Furthermore, POLG analysis optimises clinical management in the early stages of disease and reinforces the need for its evaluation before starting valproic acid treatment.

\section{Background}

Mitochondria have their own small $16.5 \mathrm{~kb}$ circular double stranded DNA encoding 22 tRNAs, 2 rRNAs and 13 polypeptides, that are absolutely essential for electron transport and oxidative phosphorylation. The remaining 1000-1500 proteins required for mitochondrial biogenesis are encoded by the nuclear genome and are imported into the mitochondria [1]. These include the proteins involved in mitochondrial DNA (mtDNA) replication, which, if defective, can produce mtDNA mutations leading to mitochondrial dysfunction and disease [2].

Among the 16 DNA polymerases identified in the eukaryotic cell so far, only DNA polymerase $\gamma(\operatorname{pol} \gamma)$ is known

\footnotetext{
* Correspondence: andre.schaller@insel.ch

'Division of Human Genetics, University Hospital Bern, Bern, Switzerland Full list of author information is available at the end of the article
}

to function in mitochondria [3-5]. The holoenzyme of human pol $\gamma$ is composed of the catalytic subunit (encoded by POLG at chromosomal locus 15q25) and a homodimer of its accessory factor (encoded by POLG2 at chromosomal locus 17q24.1) [6]. Mutations in the POLG gene have emerged as one of the most common causes of inherited mitochondrial disease in children and adults. They are responsible for a heterogeneous group of at least six major phenotypes of neurodegenerative diseases that include: 1) childhood Myocerebrohepathopathy Spectrum disorders (MCHS), 2) Alpers syndrome [7], 3) Ataxia Neuropathy Spectrum (ANS) disorders [8], 4) Myoclonus Epilepsy Myopathy Sensory Ataxia (MEMSA), 5) autosomal recessive Progressive External Ophthalmoplegia (arPEO), and 6) autosomal dominant Progressive External Ophthalmoplegia (adPEO) [9-11]. As a consequence of POLG failure,

\section{() Biomed Central}

(c) 2011 Schaller et al; licensee BioMed Central Ltd. This is an Open Access article distributed under the terms of the Creative Commons Attribution License (http://creativecommons.org/licenses/by/2.0), which permits unrestricted use, distribution, and reproduction in any medium, provided the original work is properly cited. 
accumulation of multiple mtDNA deletions and/or depletion of mtDNA in postmitotic tissues such as muscle, brain and liver is noted [12]. Additionally, various combinations of OXPHOS complex deficiencies have been reported due to POLG mutations [13-17].

Furthermore, recent studies in this area reinforced, in particular, evidence that certain mutations in POLG can lead to a range of clinical phenotypes which predispose to development of fatal liver failure after exposure to valproic acid (VPA) [15,18].

In this paper we describe the molecular genetic analysis of POLG in a 3.5 years old boy with VPA induced fatal liver failure (Alpers-Huttenlocher syndrome, AHS). The consequences of the findings were further investigated at molecular and biochemical levels.

\section{Methods \\ Patient}

A 3 7/12 year old boy, from non-consanguineous parents, with global developmental delay and ataxia was treated with valproate because of focal seizures with secondary generalisation. After 2 months, he developed acute liver failure (INR 29.95, PTT 68,9",fibrinogen <0.5 g/l, total bilirubin $152 \mu \mathrm{mol} / \mathrm{l}$, ASAT $169 \mathrm{U} / \mathrm{L}$, ALAT $139 \mathrm{U} / \mathrm{L}$, NH3 $124 \mu \mathrm{mol} / \mathrm{l})$. AHS was diagnosed based on medical history, and medical work-up demonstrated no other causes of acute liver failure. Due to the unavoidable severe progression of the neurological impairment, liver transplantation[19-21] was not proposed and the child died within two days. His parents gave informed consent for genetic studies on the collected samples (blood, skin, muscle and liver biopsies). The study protocol was approved by the local ethic commission of Bern (KEK Nr. 84/02).

\section{Mutation Analysis and DNA Sequencing}

Genomic DNA was extracted from EDTA-stabilised venous blood samples applying the QIAamp DNA kit according to the manufacturer's instructions. All 22 coding exons of the POLG were amplified from genomic DNA by means of PCR using primers listed in additional file 1. Mutation analysis of the amplified exons was performed by SSCP as described previously [22]. PCR products were sequenced employing BigDye Terminator Chemistry (Applied Biosystems) and separated on an ABI 3100 DNA Sequencer. Data were analysed with SeqScape version 2.1.1 software (Applied Biosystems).

\section{Cell culture}

Primary fibroblast cultures were established from a skin biopsy and cultured in minimal essential medium (MEM) supplemented with $10 \%$ fetal calf serum, 4 $\mathrm{mmol} / \mathrm{L}$ l-glutamine, $2 \mu \mathrm{mol} / \mathrm{L}$ uridine, $1 \mu \mathrm{mol} / \mathrm{L}$ sodium pyruvate, $50 \mathrm{U} / \mathrm{ml}$ penicillin, and $50 \mu \mathrm{g} / \mathrm{ml}$ streptomycin at $37^{\circ} \mathrm{C}$ and $5 \% \mathrm{CO}_{2}$.

\section{Transcript analysis}

Primary fibroblasts were grown for $8 \mathrm{~h}$ in $75 \mathrm{mM}$ caffeine prior to preparation of RNA in order to minimise nonsense mediated mRNA decay. Total RNA was isolated using the QIAgen RNeasy Kit according to the manufacturer's instructions. Random oligohexamer primed RNA (up to $1 \mu \mathrm{g}$ ) was reverse transcribed in a final volume of $25 \mu \mathrm{l}$ using the SuperScript II FirstStrand cDNA Synthesis System (Invitrogen) according to the manufacturer's recommendations. One-twentyfifth of single stranded cDNA was used as a template to amplify the fragment spanning exons 5-9 of POLG using the following two oligonucleotides: POLGex5 fwd 5'GCACCATGAAGGACATTCGT-3' and POLGex9 rev 5'-GCCATGACATCTTGTTGAAACT-3'. Cycling conditions using HotStar Taq DNA Polymerase (Qiagen) were $95^{\circ} \mathrm{C}$ for $15 \mathrm{~min}, 32$ cycles of $15 \mathrm{~s}$ at $95^{\circ} \mathrm{C}, 15 \mathrm{~s}$ at $58^{\circ} \mathrm{C}$ and $1 \mathrm{~min}$ at $72^{\circ} \mathrm{C}$ and a final extension step of 5 min at $72^{\circ} \mathrm{C}$. RT-PCR products were separated on an agarose gel and extracted for subsequent sequencing.

For determination of splicing efficiency of the c.1251$2 \mathrm{~A}>\mathrm{T}$ allele, cDNA was synthesised using two oligonucleotides spanning from exon 6 to exon 8: POLGex6 fwd 5'-TGTGCCCAGGACGTGTG-3' and POLGex8 rev 5'-CCGAGGTCTTCCTGATCCAT-3' essentially as describe above. The RT-PCR product was subsequently subcloned into pCR2.1-TOPO plasmid using the TOPO-TA Cloining Kit (Invitrogen). Single colonies were picked and inserts were directly amplified using M13 forward and reverse primers and subjected to DNA sequencing as described above.

\section{mtDNA quantification}

Total genomic DNA from muscle, liver and fibroblast specimens were isolated using the QIAamp DNA kit according to the manufacturer's instructions. Mitochondrial DNA content was determined by real-time PCR essentially as described by Bai and Wong [23] using SYBR Green fluorescence dye for detection of amplification. The sequence for reverse primer D-loop was replaced by the following oligonucleotide: 5'-CCGTGAGTGGTTAATAGGGTG-3'. The real-time PCR reactions for each locus (D-loop, tRNALeuUUR, ND4, ATP8 and $\beta 2 \mathrm{M}$ ) were performed in duplicate in $20 \mu \mathrm{l}$ reactions containing $10 \mu \mathrm{l} \mathrm{SYBR}{ }^{\circledR}$ Premix ExTaq (Perfect real time, Takara Bio USA), $0.5 \mu \mathrm{M}$ of each primer for a corresponding target region and $4 \mathrm{ng}$ of total genomic DNA. Real time PCR conditions were $5 \mathrm{~min}$ at $95^{\circ}$, followed by 40 cycles of $30 \mathrm{~s}$ at $95^{\circ} \mathrm{C}, 15 \mathrm{~s}$ at $60^{\circ} \mathrm{C}$ and $10 \mathrm{~s}$ at $72^{\circ} \mathrm{C}$. Fluorescent signal intensity of PCR products was recorded and analysed on a LightCycler 480 instrument (Roche Diagnostics) using LightCycler $^{\circledR} 480$ software. The threshold cycle or $C_{T}$ value within the linear exponential phase was used to construct the standard curve and to measure the original copy 
number of DNA template. Fibroblasts control values were established from patients with circumcisions or auriculoplasty, muscle and liver controls were from biopsies of patients without clinical and biochemical suspicion of a mitochondrial disorder.

\section{Biochemical assays}

Isolation of mitochondria from skin fibroblasts, preparation of skeletal muscle- and liver homogenates (600 g supernatants) were performed as described $[24,25]$. The activities of the individual respiratory chain complexes and the mitochondrial matrix marker enzyme citrate synthase were measured spectrophotometrically with an UV-1601 spectrophotometer (Shimadzu) using $1 \mathrm{ml}$ sample cuvettes thermostatically maintained at $30^{\circ} \mathrm{C}$ according to Birch-Machin and Douglas [25]. Values were estimated by the difference in activity levels measured in the presence and absence of specific inhibitors and expressed as ratios to the mitochondrial marker enzyme citrate synthase $(\mathrm{mU} / \mathrm{mU}$ citrate synthase), which was determined as described [26]. Fibroblasts control values were established from patients with circumcisions or auriculoplasty, muscle and liver controls were from biopsies of patients without clinical and biochemical suspicion of a mitochondrial disorders.

For catalytic in gel staining, $600 \mathrm{~g}$ supernatants of muscle- and liver homogenates were centrifuged (30 min, $4^{\circ} \mathrm{C}, 13000 \mathrm{rpm}$ ) and the oxidative phosphorylation complexes were solubilised by $5 \mathrm{mg}$ digitonin per $\mathrm{mg}$ protein before separation by BN-PAGE as recommended [27]. For the first dimension gradient gels of $4.5-13 \%$ were used. Catalytic staining of strips of the first dimension were performed as reported [28].

\section{Results}

Sequence analysis of patients DNA revealed compound heterozygosity for mutations in POLG. Beside the most common POLG mutation c.1399G > A/p.A467T (Figure 1A), a novel splice site mutation in intron 6 was identified (c.1251-2A > T) (Figure 1B). The splice site mutation

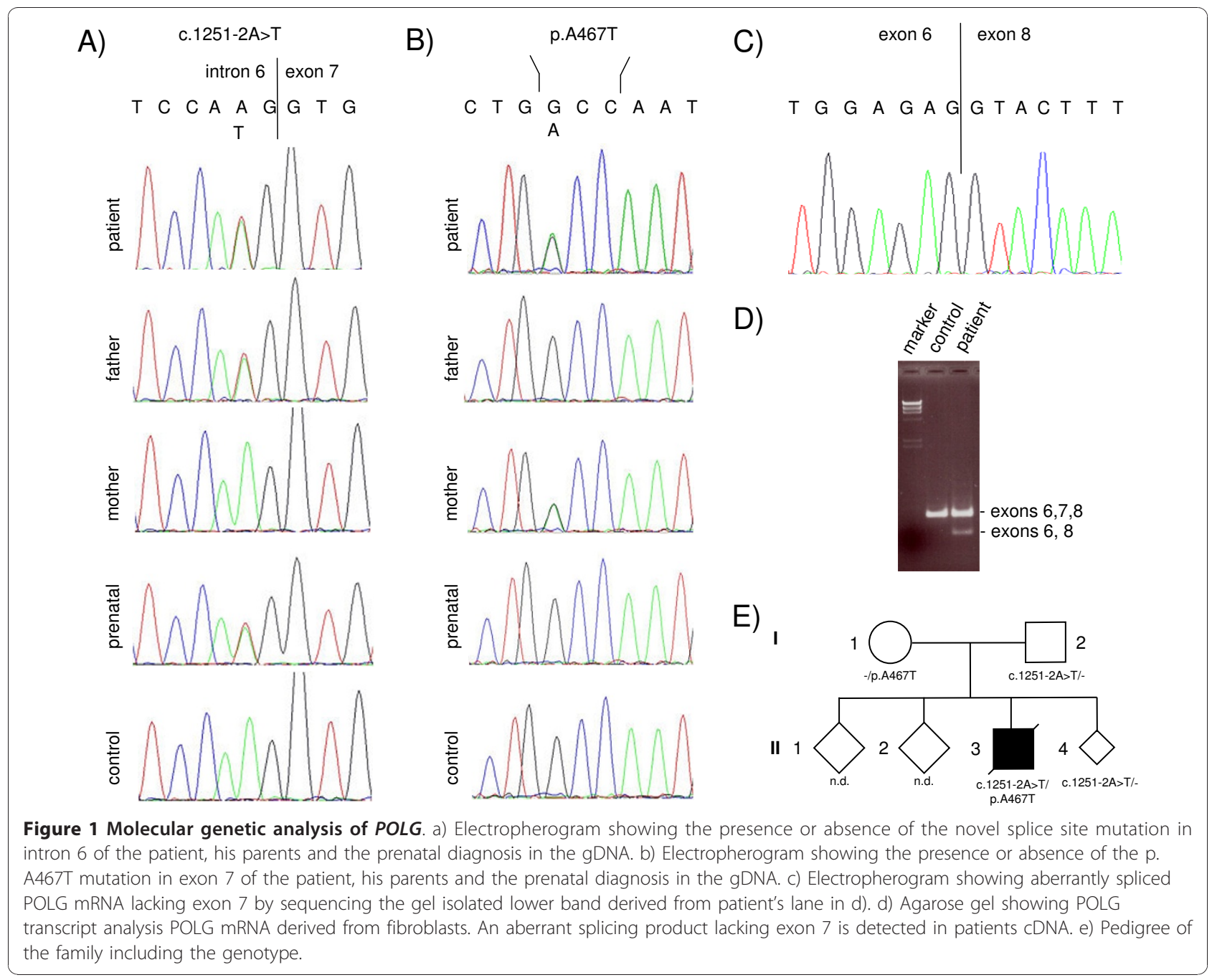


results in exon 7 skipping (Figure 1C,D), but does not affect the reading-frame, hence, the aberrantly spliced POLG transcript should not be vulnerable to undergo nonsense mediated RNA decay (NMD). To assess the degree of exon skipping for the c.1251-2A > T allele PCR products derived from $P O L G$ cDNA spanning exons 6-8 were subcloned and individual clones analysed. 77 individual clones revealed that $45 \%(34 / 77)$ of the transcripts were correctly spliced, while $55 \%$ (43/77) were aberrantly spliced. Furthermore, sequence analysis of the correctly spliced transcripts all harboured the p.A467T mutation suggesting that correct splicing of the c.1251-2A $>\mathrm{T}$ allele is completely impaired. In addition, these results also confirm that both alleles are approximately equally expressed and that indeed no NMD of the aberrantly spliced c.1251-2A $>$ T allele occurs.

Molecular genetic testing of the patient's parents identified his father as a carrier of the novel c.1251-2A $>\mathrm{T}$ splice site mutation (Figure 1A and $1 \mathrm{E}$ ) and his mother as a heterozygous carrier of the p.A467T mutation (Figure $1 \mathrm{~B}$ and $1 \mathrm{E}$ ).

To further investigate the consequences of the POLG mutations, the mtDNA was quantitatively and qualitatively assessed using a combined qPCR approach. The analysis of DNA extracted from fibroblasts, liver and skeletal muscle revealed no deletions in the mtDNA in the tissues tested (results not shown). However, various degrees of mtDNA depletion were detected in the three tested tissues (Figure 2). In fibroblasts, the amount of mtDNA (820 molecules per cell) was insignificantly lower relative to the control mean (832 molecules per cell) (Figure 2A), whereas a mtDNA depletion of $22 \%$ was detected in muscle relative to the control mean (Figure $2 \mathrm{~B}$ ). The most pronounced mtDNA depletion was measured in the patient's liver tissue where $85 \%$ of the mtDNA was depleted relative to the control mean (Figure 2C).

In order to assess the consequences of the mtDNA depletion on the OXPHOS activities, CI-V have been assayed. In the mitochondria from patient's fibroblasts, liver- and skeletal muscle tissues, OXPHOS enzymes (I, II, III, IV and V) were measured spectrophotometrically. In fibroblasts all activities were normal. The activities of complex I, III and IV were decreased in liver. In skeletal muscle, the activity of complex IV was decreased and the activities for complex I and II were in the lower control range (table 1). Catalytic staining in the BN-PAGE gel revealed a severe reduction of intensity for complex IV in liver and muscle (Figure 3). The intensities for complex I were also reduced in both tissues, but to a lesser extent. Staining for complex II was normal and comparable to the control (Figure 3).

\section{Discussion}

Mitochondrial depletion syndromes (MDS) are severe disorders often presenting themselves in early infancy or

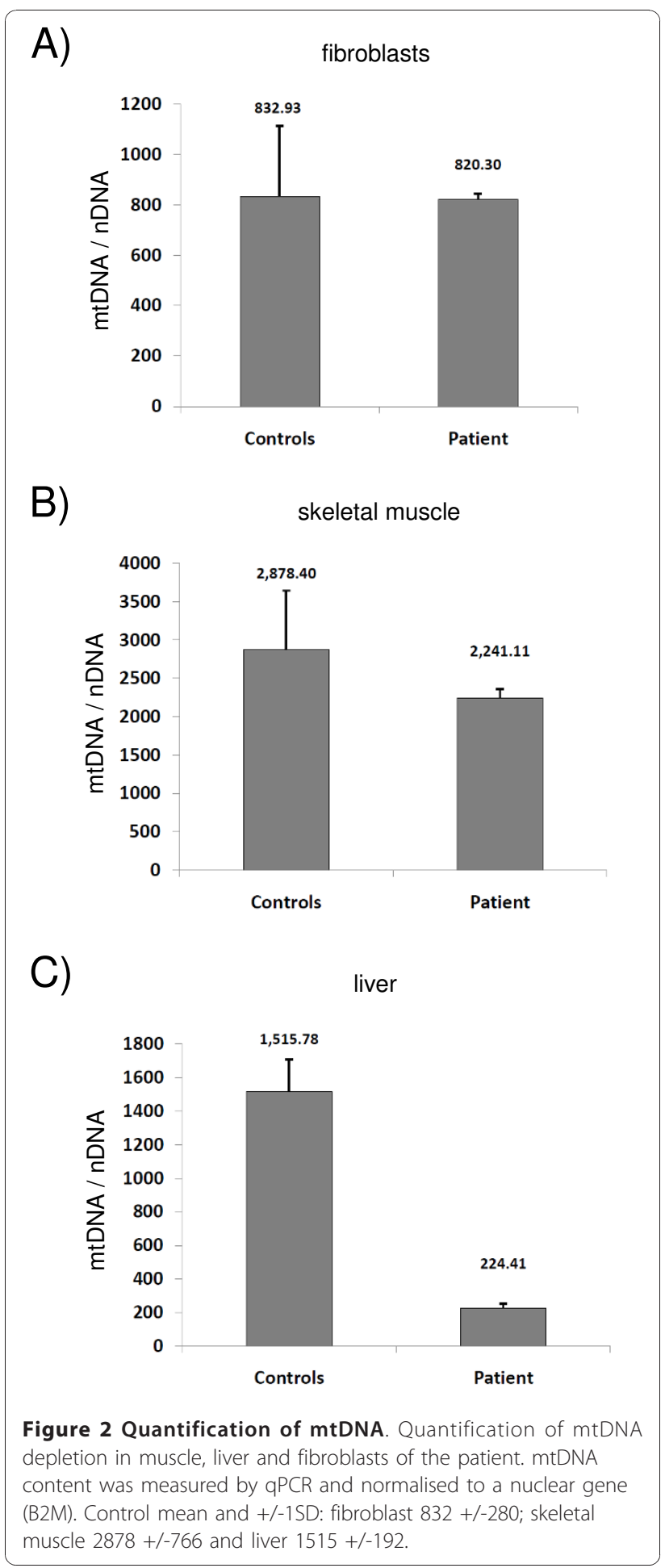

childhood. They comprise of a variety of features including profound weakness, encephalopathy, seizures and liver failure. A particular form of a hepatocerebral depletion is known as Alpers-Huttenlocher Syndrome (AHS) characterised by progressive neuronal degeneration in childhood, explosive onset of seizures, developmental 
Table 1 Patient's OXPHOS activities measured in three different tissues

\begin{tabular}{lcccccc}
\hline \multicolumn{1}{c}{ Enzymes } & Patient & Controls $(\mathbf{n}=\mathbf{2 2})$ & Patient & Controls $(\mathbf{n}=\mathbf{2 6})$ & \multicolumn{2}{c}{ Liver homogenate } \\
\hline Complex I & 0.29 & $0.19-0.46(0.29+/-0.07)$ & $0.16 / 0.13^{*}$ & $0.12-0.28(0.19+/-0.04)$ & $\mathbf{0 . 0 0 7 / 0 . 0 0 8 ^ { * }}$ & $0.22-0.76(0.43+/-0.2)$ \\
Complex II & 0.25 & $0.17-0.52(0.33+/-0.09)$ & $0.13 / 0.15^{*}$ & $0.14-0.36(0.21+/-0.05)$ & $0.68 / 0.75^{*}$ & $0.59-2.11(1.35+/-0.45)$ \\
Complex III & 0.42 & $0.35-0.87(0.6+/-0.15)$ & 0.74 & $0.55-1.11(1.16+/-0.28)$ & $\mathbf{0 . 2 6 / 0 . 3 *}$ & $0.54-2.16(1.47+/-0.49)$ \\
Complex IV & 0.49 & $0.42-1.11(0.75+/-0.18)$ & $\mathbf{0 . 2 7 / 0 . 1 7 ^ { * }}$ & $0.57-1.77(0.78+/-0.15)$ & $\mathbf{0 . 3 5 / 0 . 4 2 *}$ & $0.74-5.17(2.1+/-1.2)$ \\
Complex V & 0.16 & $0.14-0.42(0.22+/-0.08)$ & 0.19 & $0.19-0.65(0.39+/-0.13)$ & 0.42 & $0.25-1.14(0.58+/-0.28)$ \\
Citrate synthase & 172 & $106-317(184+/-43)$ & 124 & $70-169(105+/-25)$ & 68 & $21-40(31+/-6.5)$ \\
\hline
\end{tabular}

Activities of the respiratory chain complexes are normalised to citrate synthase (CS) and are expressed as $\mathrm{mU} / \mathrm{mg} \mathrm{mitochondrial}$ protein. Mean value (+/- $1 \mathrm{SD}$ ) of controls are indicated in brackets. Profound deficiencies below the range of controls are shown in bold. $\mathrm{n}=$ number of controls; ${ }^{*}=$ measured as duplicate.

delay, cortical blindness and spasticity followed by fulminant liver failure and parieto-occipital cerebral atrophy [29]. In AHS a depletion of the mtDNA is commonly observed, which is considered as a secondary phenomenon due to primary POLG mutations, which in turn leads to a defective system for oxidative phosphorylation (OXPHOS) [7]. However, POLG mutations in these phenotypes are not exclusive to the observed mtDNA damage.

Currently, there is no clear link between a particular POLG genotype and the resulting phenotype. However, with the characterisation of an increasing number of reported POLG mutations, patterns start to emerge. All AHS affected patients reported so far carry one of two linker mutations (p.A467T or p.W748S) in combination with either another linker mutation or a mutation located in the polymerase domain [19], whereas the p. A467T mutation is the most common mutation identified in POLG. It is present in all major POLG-related diseases: Alpers-Huttenlocher disease, ataxia-neuropathy syndromes and PEO.

Our patient showed a severe clinical phenotype and died due to valproate induced fatal acute liver failure. Analysis of the mtDNA content revealed a severe

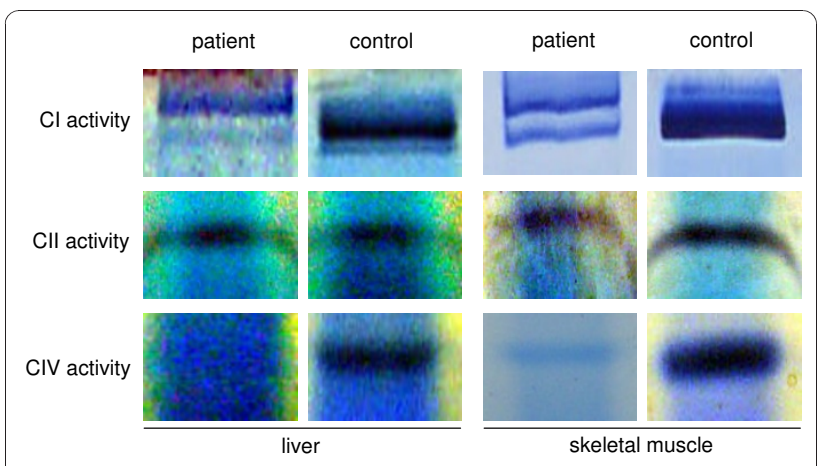

Figure 3 Catalytic staining of OXPHOS-complexes. Catalytic staining following separation of the OXPHOS-complexes by $\mathrm{BN}$ PAGE showing decreased intensities of the bands corresponding to complex I and IV in patients liver and skeletal muscle. The bands corresponding to complex II are comparable to the control. depletion in liver (approx. 90\%), a less pronounced depletion in skeletal muscle (approx. 25\%) and no depletion in fibroblasts. As a consequence, a combined respiratory chain defect involving complexes I, III and IV was measured in liver cells. In skeletal muscle, only complex IV showed a decreased activity suggesting that complex IV is the most vulnerable in mtDNA depletion syndromes. However, it is unknown which factors contribute to the tissue specificity of mitochondrial dysfunction in patients carrying POLG mutations. The finding of normal OXPHOS enzyme activities in our patient is also a common observation in other patients [16] and emphasises the need to investigate primary tissues as fibroblast analysis may give misleading results. The cellular mtDNA content may be an indicator of the underlying molecular mechanism linking genotype to phenotype and explaining the patient's acute liver failure.

Molecular genetic analysis of POLG revealed two linker region mutations, the c.1399G > A (p.A467T) and a novel splice site mutation c.1251-2A $>\mathrm{T}$ affecting the highly conserved splice acceptor site in intron 6. Analysis of the patient's parents confirmed that these mutations are present in trans in the patient. These findings are in good agreement with the observation that patients with two linker mutations exhibit a more severe clinical phenotype than patients carrying one linker and one polymerase domain mutation [30]. Furthermore, detection of the primary mutations in POLG did not only confirm the clinical diagnosis of Alpers syndrome, but also allowed a reliable prenatal diagnosis for the parents in the following pregnancy (Figure 1A and 1B).

Several inborn errors of metabolism are known to represent a risk factor for severe idiosyncratic reactions to VPA, including liver toxicity [31]. Many studies have focused on the interaction between VPA and mitochondrial function in general and mitochondrial disorders such as Alpers-Syndrome in particular, as conditions predisposing to severe VPA toxicity [32]. Recent studies gave evidence that POLG mutations can lead to a range of clinical phenotypes which predispose to the development of fatal liver failure after exposure to VPA $[15,18]$. 
Nevertheless, a single case report suggests that there may be mutations in the POLG gene associated with reversibility of the hepatotoxicity [33], The presented study extends the list of POLG mutations associated with VPA hepatotoxicity.

\section{Conclusion}

Screening of $P O L G$ gene in mitochondrial diseases is helpful for confirming the diagnosis, especially in the case of AHS. POLG analysis offers the added benefits of carrier testing, prenatal diagnosis, postnatal pre-symptomatic diagnosis of siblings and optimised clinical management from the early stages of disease. Further this study contributes to the pathomechanism of POLG mutations and expands the knowledge of the genotypephenotype correlation.

\section{Additional material}

\section{Additional file 1: Primer sequences for PCR amplification of POLG} exons

\section{Acknowledgements}

We are indebted to the family participating in this study. We thank A. Häberli for excellent technical assistance. This work was supported by a grant of the Novartis Research Foundation to AS.

\section{Author details \\ ${ }^{1}$ Division of Human Genetics, University Hospital Bern, Bern, Switzerland. ${ }^{2}$ Institute of Clinical Chemistry, University Hospital Bern, Bern, Switzerland. ${ }^{3}$ Department of Paediatrics, University of Geneva Children's Hospital, Geneva, Switzerland. ${ }^{4}$ Paediatric Surgery Unit, University of Geneva Children's Hospital, Geneva, Switzerland. ${ }^{5}$ Paediatric Surgery Unit, Hôpital Necker- Enfants malades, Paris, France.}

\section{Authors' contributions}

AS participated in the design and coordination of the study, performed genetic and data analyses and drafted the manuscript. CBJ performed genetic and data analyses and participated in drafting the manuscript. DH and JMN performed biochemical and data analyses and participated in the study design and in drafting the manuscript. IK, CC and DCB performed the clinical investigations and participated in its design and in drafting the manuscript. SG participated in genetic data analyses and in the design and drafting the manuscript. All authors read and approved the final manuscript

\section{Competing interests}

This study has been funded by an unrestricted grant from Novartis. The authors have no conflict of interest with the source of funding of the study.

Received: 20 June 2010 Accepted: 14 January 2011

Published: 14 January 2011

\section{References}

1. Calvo S, Jain M, Xie X, Sheth SA, Chang B, Goldberger OA, Spinazzola A, Zeviani M, Carr SA, Mootha VK: Systematic identification of human mitochondrial disease genes through integrative genomics. Nat Genet 2006, 38(5):576-582.

2. Copeland WC: Inherited mitochondrial diseases of DNA replication. Annu Rev Med 2008, 59:131-146.

3. Bebenek K, Kunkel TA: Functions of DNA polymerases. Adv Protein Chem 2004, 69:137-165.
4. Ropp PA, Copeland WC: Cloning and characterization of the human mitochondrial DNA polymerase, DNA polymerase gamma. Genomics 1996, 36(3):449-458.

5. Sweasy JB, Lauper JM, Eckert KA: DNA polymerases and human diseases. Radiat Res 2006, 166(5):693-714.

6. Yakubovskaya E, Chen Z, Carrodeguas JA, Kisker C, Bogenhagen DF: Functional human mitochondrial DNA polymerase gamma forms a heterotrimer. J Biol Chem 2006, 281(1):374-382.

7. Naviaux RK, Nguyen KV: POLG mutations associated with Alpers' syndrome and mitochondrial DNA depletion. Ann Neurol 2004, 55(5):706-712.

8. Winterthun S, Ferrari G, He L, Taylor RW, Zeviani M, Turnbull DM, Engelsen BA, Moen G, Bindoff LA: Autosomal recessive mitochondrial ataxic syndrome due to mitochondrial polymerase gamma mutations. Neurology 2005, 64(7):1204-1208.

9. Lamantea E, Tiranti V, Bordoni A, Toscano A, Bono F, Servidei S, Papadimitriou A, Spelbrink H, Silvestri L, Casari G, et al: Mutations of mitochondrial DNA polymerase gammaA are a frequent cause of autosomal dominant or recessive progressive external ophthalmoplegia. Ann Neurol 2002, 52(2):211-219.

10. Van Goethem G, Dermaut B, Lofgren A, Martin JJ, Van Broeckhoven C: Mutation of POLG is associated with progressive external ophthalmoplegia characterized by mtDNA deletions. Nat Genet 2001, 28(3):211-212.

11. Van Goethem G, Martin JJ, Dermaut B, Lofgren A, Wibail A, Ververken D, Tack P, Dehaene I, Van Zandijcke M, Moonen M, et al: Recessive POLG mutations presenting with sensory and ataxic neuropathy in compound heterozygote patients with progressive external ophthalmoplegia. Neuromuscul Disord 2003, 13(2):133-142.

12. Milone M, Brunetti-Pierri N, Tang LY, Kumar N, Mezei MM, Josephs K, Powell S, Simpson E, Wong LJ: Sensory ataxic neuropathy with ophthalmoparesis caused by POLG mutations. Neuromuscul Disord 2008, 18(8):626-632.

13. Ferrari G, Lamantea E, Donati A, Filosto M, Briem E, Carrara F, Parini R, Simonati A, Santer R, Zeviani M: Infantile hepatocerebral syndromes associated with mutations in the mitochondrial DNA polymerasegammaA. Brain 2005, 128(Pt 4):723-731.

14. Gonzalez-Vioque E, Blazquez A, Fernandez-Moreira D, Bornstein B, Bautista J, Arpa J, Navarro C, Campos Y, Fernandez-Moreno MA, Garesse R, et al: Association of novel POLG mutations and multiple mitochondrial DNA deletions with variable clinical phenotypes in a Spanish population. Arch Neurol 2006, 63(1):107-111.

15. Horvath R, Hudson G, Ferrari G, Futterer N, Ahola S, Lamantea E, Prokisch H, Lochmuller H, McFarland R, Ramesh V, et al: Phenotypic spectrum associated with mutations of the mitochondrial polymerase gamma gene. Brain 2006, 129(Pt 7):1674-1684.

16. de Vries MC, Rodenburg RJ, Morava E, van Kaauwen EP, ter Laak H, Mullaart RA, Snoeck IN, van Hasselt PM, Harding P, van den Heuvel LP, et al: Multiple oxidative phosphorylation deficiencies in severe childhood multi-system disorders due to polymerase gamma (POLG1) mutations. Eur J Pediatr 2007, 166(3):229-234

17. Sarzi E, Bourdon A, Chretien D, Zarhrate M, Corcos J, Slama A, CormierDaire $V$, de Lonlay $P$, Munnich A, Rotig A: Mitochondrial DNA depletion is a prevalent cause of multiple respiratory chain deficiency in childhood. $J$ Pediatr 2007, 150(5):531-534, 534 e531-536.

18. Tzoulis C, Engelsen BA, Telstad W, Aasly J, Zeviani M, Winterthun S, Ferrari $G$, Aarseth $J H$, Bindoff $L A$ : The spectrum of clinical disease caused by the A467T and W748S POLG mutations: a study of 26 cases. Brain 2006, 129(Pt 7):1685-1692.

19. Nguyen KV, Ostergaard E, Ravn SH, Balslev T, Danielsen ER, Vardag A, McKiernan PJ, Gray G, Naviaux RK: POLG mutations in Alpers syndrome. Neurology 2005, 65(9):1493-1495.

20. Delarue A, Paut O, Guys JM, Montfort MF, Lethel V, Roquelaure B, Pellissier JF, Sarles J, Camboulives J: Inappropriate liver transplantation in a child with Alpers-Huttenlocher syndrome misdiagnosed as valproateinduced acute liver failure. Pediatr Transplant 2000, 4(1):67-71.

21. Thomson M, McKiernan P, Buckels J, Mayer D, Kelly D: Generalised mitochondrial cytopathy is an absolute contraindication to orthotopic liver transplant in childhood. J Pediatr Gastroenterol Nutr 1998, 26(4):478-481. 
22. Liechti-Gallati S, Schneider V, Neeser D, Kraemer R: Two buffer PAGE system-based SSCP/HD analysis: a general protocol for rapid and sensitive mutation screening in cystic fibrosis and any other human genetic disease. Eur J Hum Genet 1999, 7(5):590-598.

23. Bai RK, Wong LJ: Simultaneous detection and quantification of mitochondrial DNA deletion(s), depletion, and over-replication in patients with mitochondrial disease. J Mol Diagn 2005, 7(5):613-622.

24. Rustin P, Chretien D, Bourgeron T, Gerard B, Rotig A, Saudubray JM, Munnich A: Biochemical and molecular investigations in respiratory chain deficiencies. Clin Chim Acta 1994, 228(1):35-51.

25. Birch-Machin MA, Turnbull DM: Assaying mitochondrial respiratory complex activity in mitochondria isolated from human cells and tissues. Methods Cell Biol 2001, 65:97-117.

26. Shepherd D, Garland PB: The kinetic properties of citrate synthase from rat liver mitochondria. Biochem J 1969, 114(3):597-610.

27. Schagger $\mathrm{H}$ : Blue-native gels to isolate protein complexes from mitochondria. Methods Cell Biol 2001, 65:231-244.

28. Zerbetto E, Vergani L, Dabbeni-Sala F: Quantification of muscle mitochondrial oxidative phosphorylation enzymes via histochemical staining of blue native polyacrylamide gels. Electrophoresis 1997 18(11):2059-2064.

29. Huttenlocher PR, Solitare GB, Adams G: Infantile diffuse cerebral degeneration with hepatic cirrhosis. Arch Neurol 1976, 33(3):186-192.

30. Stewart JD, Tennant S, Powell H, Pyle A, Blakely EL, He L, Hudson G, Roberts M, du Plessis D, Gow D, et al: Novel POLG1 mutations associated with neuromuscular and liver phenotypes in adults and children. $J$ Med Genet 2009, 46(3):209-214.

31. Konig SA, Siemes H, Blaker F, Boenigk E, Gross-Selbeck G, Hanefeld F, Haas N, Kohler B, Koelfen W, Korinthenberg R, et al: Severe hepatotoxicity during valproate therapy: an update and report of eight new fatalities. Epilepsia 1994, 35(5):1005-1015.

32. Silva MF, Aires CC, Luis PB, Ruiter JP, ljlst L, Duran M, Wanders RJ, Tavares de Almeida I: Valproic acid metabolism and its effects on mitochondrial fatty acid oxidation: A review. J Inherit Metab Dis 2008, 31(2):205-216.

33. McFarland R, Hudson G, Taylor RW, Green SH, Hodges S, McKiernan PJ, Chinnery PF, Ramesh V: Reversible valproate hepatotoxicity due to mutations in mitochondrial DNA polymerase gamma (POLG1). Arch Dis Child 2008, 93(2):151-153.

\section{Pre-publication history}

The pre-publication history for this paper can be accessed here: http://www.biomedcentral.com/1471-2377/11/4/prepub

doi:10.1186/1471-2377-11-4

Cite this article as: Schaller et al: Molecular and biochemical characterisation of a novel mutation in POLG associated with Alpers syndrome. BMC Neurology 2011 11:4.

\section{Submit your next manuscript to BioMed Central and take full advantage of:}

- Convenient online submission

- Thorough peer review

- No space constraints or color figure charges

- Immediate publication on acceptance

- Inclusion in PubMed, CAS, Scopus and Google Scholar

- Research which is freely available for redistribution

Submit your manuscript at www.biomedcentral.com/submit
Biomed Central 